\title{
More on imagery and the recall of adjectives and nouns from meaningful prose
}

\author{
CHARLES DE VITO \\ and \\ ANDREW MANFRED OLSON* \\ Brooklyn College, New York, N.Y. 11210
}

Following Morris \& Reid (1972), two groups of Ss were each given a different version of the same passage to read for comprehension. Version $\mathrm{H}$ had high-imagery adjectives, Version L had low-imagery adjectives. Both groups were then tested for free recall of adjectives and adjective-cued recall of nouns. Significant differences were found in mean number of adjectives and mean number of nouns recalled. A direct function was implied between number of adjectives recalled and adjectives correctly recalled and then correctly paired with nouns.

Morris \& Reid (1972), extending the work of Kirchner (1969) and Morris \& Reid (1971), investigated the hypothesis that nouns associated with high-imagery adjectives would be recalled more frequently than nouns associated with low-imagery adjectives in a prose passage. Their results indicated no significant differences between recall of nouns for the two versions of the prose passage in which high-imagery $(\mathrm{H})$ and low-imagery $(\mathrm{L})$ adjectives were used. However, they did find a significant difference between recall of adjectives, with $26 \%$ of the $L$ and $44 \%$ of the $H$ version adjectives recalled. Since, when Ss were then given the list of nouns, cued recall of adjectives yielded less than $50 \%$ recalled, the finding of no significant differences in the recall of nouns may have been due to the unavailability of the "cueing" adjectives during free recall of nouns.

The present study modifies the design of Experiment I of Morris \& Reid (1972) by requiring free recall of adjectives and then cued recall of nouns. The greater availability of cueing adjectives during noun recall should lead to a significant difference in noun recall.

\section{METHOD}

Subjects

The Ss were 43 male and female Brooklyn College students, members of two introductory psychology classes, who volunteered to participate. Twenty-one Ss were presented with Version $H, 22$ with Version $L$.

\section{Materials}

The passage was the same passage used by Morris \& Reid (1972), E. M. Forster's short story, The Road from Colonus, with adjectives deleted. Version $L$ contained 18 low-imagery adjectives (mean $=3.12)$ and Version $\mathrm{H}$ contained 18 high-imagery adjectives (mean $=5.46$ ). The high-I and low-I adjectives were also the same as those used by Morris and Reid, obtained by Morris \& Reid (1971) following the procedure of Paivio, Yuille, \& Madigan (1968).

*Special thanks to Solomon Weinstock for his comments on the manuscript.

\section{Procedure}

The procedure was essentially that of Morris \& Reid (1972): Half of each class received one of the two versions by random assignment. At a signal, they were instructed to "read the passage carefully, since you will be asked to answer questions about it." At the end of a 2-min interval, they were told to turn the passage face down and to "write as many adjectives from the passage as you can remember." Three minutes were allowed for free recall of adjectives. Then a form was distributed giving the 18 adjectives (either high-I or low-I) which had preceded the nouns in the passage. Ss instructions were: "For each adjective write down the noun that followed it in the passage." Three minutes were allowed for cued recall of nouns.

\section{RESULTS \\ Adjective Recall}

The mean number of adjectives correctly recalled in Version $\mathrm{H}$ was 6.38 and in Version L, 2.41. Using The Mann-Whitney $U$ test, the difference was significant $(U=26.5, z=5.01, p<.0001)$. For each $S$ in both Group $\mathrm{H}$ and Group L, the proportion of adjectives correctly recalled and then correctly paired with nouns over total adjectives was computed. The mean proportion for Group $\mathrm{H}$ was .60 , for Group L, .58. Using a Mann-Whitney $U$ test, there was no significant difference.

\section{Noun Recall}

The mean number of nouns correctly recalled (nouns correctly recalled and correctly paired) was 6.48 for Group H. For Group L, it was 3.05. A Mann-Whitney U test showed a significant difference $(U=56, z=4.29$, $p<.0001$ ).

During analysis of $\mathrm{S}$ protocols, it was discovered that in Version $\mathrm{H}$ a group of adjectives (color) clustered in the free recall task. In order to avoid the possibility that this clustering confounded the results, we removed these adjectives and their corresponding nouns from Version $\mathbf{H}$ and these same nouns and their corresponding adjectives from Version L. Thus, scores were recomputed without these items. Comparisons, as above, were made on the new scores and the results were identical in terms of significance.

\section{Corrected Adjective Recall}

The mean number of adjectives correctly recalled in Version $H$ was 3.19 , in Version $L, 1.77$. Using the Mann-Whitney $U$ test, the difference was significant $(\mathrm{U}=129.5, \mathrm{z}=2.52, \mathrm{p}<.02)$. For each $\mathrm{S}$ in both Groups $\mathrm{H}$ and $\mathrm{L}$, the proportion of adjectives correctly recalled and then correctly paired with nouns over total adjectives was computed. The mean proportion for Group $\mathrm{H}$ was .75, for Group L, .62. Using a Mann-Whitney $U$ test, there was no significant difference. 


\section{Corrected Noun Recall}

The mean number of nouns correctly recalled was 4.71 for Group $\mathrm{H}$ and 2.32 for Group L. A Mann-Whitney $U$ test showed a significant difference $(\mathrm{U}=62.5, \mathrm{z}=4.15, \mathrm{p}<.0001)$.

\section{DISCUSSION}

For a prose passage, these results again show that imagery value affects adjective recall (Morris \& Reid, 1972) and also support the finding that noun recall is a function of adjective imagery value (assuming imagery to be highly related to vividness). [This assumption appears to be legitimate given the great similarity in their operational definitions (Kirchner, 1969).] Furthermore, there was no significant ditference in the mean proportion of adjectives correctly recalled and then correctly paired with nouns, over total adjectives correctly recalled between Group $\mathrm{H}$ and Group L. This implies a direct function between total adjectives recalled and adjectives correctly recalled and then correctly paired.

\section{REFERENCES}

Kirchner, E. P. Vividness of adjectives and the recall of meaningful verbal material. Psychonomic Science, 1969, 15, 71-72.

Morris, P. E., \& Reid, R. L. Imagery and compatibility of pairing in the free recall of adjective-noun pairs. Quarterly Journal of Experimental Psychology, 1971, 23, 393-398.

Morris, P. E., \& Reid, R. L. Imagery and the recall of adjectives and nouns from meaningful prose. Psychonomic Science, $1972,27,117-118$.

Paivio, A., Yuille, J. C. \& Madigan, S. Concreteness, imagery and meaningfulness values for 925 nouns. Journal of Experimental Psychology, 1968, 76, 1-25.

(Received for publication March 19, 1973.) 